Disponível em:

http://editora.unoesc.edu.br/index.php/race

RACE, Joaçaba, v. 16, n. 3, p. 235-258, edição especial, 2017

\title{
PROCESSO SELETIVO PÚBLICO PARA ESCOLHA DE SECRETÁRIO MUNICIPAL: ANÁLISE DA EXPERIÊNCIA DA CIDADE DE LONDRINA, PR
}

Public selection process for choosing the municipal secretary of education: analysis of the experience of the City of Londrina, $P R$

Thiago Miquel Lamelo

E-mail: thl564@student.hks.harvard.edu Mestrando em Políticas Públicas pela Kennedy School of Government, Universidade de Harvard, EUA; Graduado em Administração pela Universidade de São Paulo.

Joice Toyota Mendes

E-mail: joice.toyota@vetorbrasil.org Mestre em Educação pela Universidade de Stanford, EUA; Graduada em Engenharia da Computação pela Universidade de São Paulo; Diretora Executiva e cofundadora do Vetor Brasil. Endereço para contato: WeWork Paulista, Avenida Paulista, n. 1374, $11^{\circ}$ andar, Bela Vista, 01310-100, São Paulo, São Paulo, Brasil.

Maria Fernanda Alessio

E-mail: mfalessio@gmail.com Doutora em Administração Pública e Governo pela Fundação Getúlio Vargas; Mestre em Administração Pública e Governo pela Fundação Getúlio Vargas; Coordenadora de Estratégias de Gestão da Secretaria Municipal de Gestão da Prefeitura de São Paulo.

\section{Tâmara Karoline Barros de Andrade} E-mail: tamara@vetorbrasil.org Mestranda em Gestão e Políticas Públicas pela Fundação Getúlio Vargas; Pós-graduada em Gestão Estratégica de Pessoas pela Fundação Instituto de Administração da Universidade de São Paulo; Graduada em Psicologia pela Pontifícia Universidade Católica de São Paulo; Diretora de Seleção e Desenvolvimento de Talentos do Vetor Brasil.

Artigo recebido em 03 de agosto de 2017. Aceito em 13 de novembro de 2017. 


\section{Resumo}

Neste trabalho discute-se sobre a experiência de seleção pública para o cargo de Secretário Municipal de Educação de Londrina, no Paraná, enfatizando a relevância de dois aspectos essenciais: o tema da alta direção pública, ainda pouco explorado pela literatura no País, e o sucesso do estabelecimento de um modelo de seleção baseado na aferição prévia das competências de gestão como insumo para subsidiar nomeações políticas de natureza discricionária. Na análise dessa iniciativa pioneira, demonstra-se o diálogo existente entre a experiência de Londrina e a literatura sobre o tema da alta direção pública, explorando três dimensões: o conceito de dirigente ou líder público, a caracterização dos espaços institucionais em que atuam e o papel das competências gerenciais como eixo central para a realização de processos de escolha desses profissionais. No trabalho também se detalham as etapas que constituíram o processo de seleção em Londrina e se indicam os atores envolvidos nesse processo. Em seguida, relacionam-se os principais avanços e desafios que caracterizam um processo seletivo dessa natureza e se oferecem recomendações orientadas a gestores públicos que almejem replicar a iniciativa. A metodologia adotada para a análise do caso foi a de observação participante, considerando o envolvimento dos autores na concepção e implantação dessa experiência.

Palavras-chave: Gestão de pessoas. Seleção. Processo seletivo. Competências. Dirigentes públicos.

\section{Abstract}

This project discusses the experience of the public selection for the title of Municipal Secretary of Education of Londrina, state of Paraná, emphasizing the relevance of two main aspects: the topic of the high public administration, still little explored by the country's literature, and the success of the establishment of a selection model, based on the previous assessment of the management competencies as material to finance political appointments of discretionary nature. In our analysis of this pioneer initiative, we will demonstrate the dialog existing between the Londrina's experience and literature about the topic of high public administration, exploring three dimensions: the concept of director and public leader, the characterization of the institutional spaces where they act and the role of managerial competencies as central axis for the realization of the selection processes of these professionals. The project also details the steps that had formed the selection process in Londrina and indicates who are the actors involved with this process. Next, it relates the main advances and challenges that characterize a selection process of this nature and offers recommendations destined to public managers that want to replicate this initiative. The methodology adopted for the case analysis was the participant observation, considering the involvement of the authors in this experience's conception and deployment.

Keywords: Human resources management. Selection. Selection process. Competencies. Public officials. 


\section{INTRODUÇÃO}

No presente artigo apresenta-se a experiência pioneira de seleção pública, profissional e aberta para o cargo de Secretário de Educação, realizada em Londrina, Paraná, entre os meses de outubro e dezembro de 2016. O objetivo foi explorar o diálogo existente entre as ações desenvolvidas no âmbito dessa iniciativa e a literatura nacional e internacional sobre o tema da alta direção pública, bem como demonstrar os principais avanços e desafios da experiência analisada.

Cabe ressaltar dois aspectos fundamentais que indicam a relevância deste trabalho para interessados no tema. Em primeiro lugar, o texto parte de uma referência teórica ainda pouco explorada pela literatura no Brasil, já que o reconhecimento da figura do dirigente público como categoria analítica distinta das figuras tradicionais do político e do burocrata vem sendo defendido por alguns autores (ALESSIO, 2017; PACHECO, 2008; LONGO, 2007) como forma de melhor compreender tais atores em ação no âmbito das estruturas governamentais. Em segundo lugar, o objeto empírico analisado neste estudo constitui experiência pioneira no País, já que a lacuna identificada na literatura se reflete nas experiências em curso no Brasil, tanto em nível federal - neste último caso, avaliada por estudos recentes sobre o tema (ALESSIO, 2017) -, quanto em nível subnacional, no qual são escassas as evidências de experiências de seleção pública orientadas a cargos do alto escalão governamental de estados e municípios.

Em linhas gerais, a seleção para Secretário Municipal de Educação de Londrina teve origem a partir do convite feito ao Vetor Brasil pelo deputado federal e prefeito eleito de Londrina para a gestão 2017-2020, Marcelo Belinati (PP/PR). O projeto foi idealizado pelo prefeito e pelo deputado federal Alex Canziani (PTB/PR), presidente da Frente Parlamentar Mista da Educação, interessados em profissionalizar o processo de escolha de um dos cargos mais importantes da Prefeitura de Londrina a partir da adoção e da aferição de um conjunto de critérios como condição para a nomeação do Secretário de Educação. O cargo em comissão mantém seu caráter discricionário, sujeito à livre nomeação e exoneração pela autoridade política; o que muda é a adoção, por essa autoridade, de um processo racional e sistematizado de escolha orientado a garantir que o melhor profissional seja nomeado e responsabilizado para o desempenho e a entrega dos resultados desejados no âmbito dessa função de direção.

Tal iniciativa foi concebida e operacionalizada no âmbito do Programa Líderes de Gestão Pública, desenvolvido pelo Vetor Brasil, organização sem fins lucrativos que seleciona e desenvolve talentos para governos em todo o Brasil. Tal Programa tem por objetivo atrair lideranças para altos cargos do setor público por meio de um 
processo seletivo norteado por evidências e metodologia profissional, em detrimento de motivações político-partidárias. O case de Londrina, no entanto, diferenciou-se dos demais processos seletivos realizados pelo Programa Líderes de Gestão Pública, pois, a pedido do prefeito e do deputado anteriormente mencionados, foi realizado de forma pública e amplamente divulgado em meios de comunicação locais e nacionais, a fim de tornar-se um exemplo para outras gestões em todo o País.

O Vetor Brasil foi responsável por realizar a pré-seleção dos candidatos, indicando os nomes dos finalistas ao prefeito, responsável pela escolha e decisão final. A seleção foi bastante competitiva, contando com 129 inscritos, avaliados em sete etapas, dentre as quais uma sabatina com profissionais da rede municipal de educação e uma entrevista com uma banca avaliadora composta por notórias lideranças da educação brasileira.

O artigo está estruturado da seguinte forma: na segunda seção, é discutida a relação existente entre a literatura recente sobre o tema da direção pública profissional e o caso empírico analisado; na terceira, detalha-se a experiência de Londrina, descrevendo as etapas do processo seletivo realizado. Em seguida, são apresentados os aprendizados e os desafios que o caso de Londrina oferece para estudos e experiências relacionadas ao tema da seleção para cargos de direção no setor público e, a título de conclusão, apresentam-se as considerações finais.

\section{REFERENCIAL TEÓRICO}

Nesta seção, abordam-se três aspectos centrais: quem são e em que espaços atuam os dirigentes públicos, quais as dimensões constitutivas de um sistema de alta direção pública e qual a importância das competências gerenciais para esta literatura. Paralelamente, relaciona-se cada um desses aspectos ao caso específico de Londrina.

\subsection{LIDERANÇAS PÚBLICAS: QUEM SÃO E EM QUE ESPAÇO ATUAM?}

A literatura internacional vem dando crescente ênfase ao reconhecimento da figura do dirigente público, compreendido como um ator específico no âmbito das estruturas governamentais. Orientados à eficiência, à entrega de resultados e à criação de valor público, tais atores vêm sendo tratados como figuras analíticas distintas dos atores tradicionais abordados pela literatura: políticos e burocratas. 
A análise da literatura indica a existência de diferentes conceitos para o dirigente público, que não são necessariamente coincidentes, mas complementares. Alessio (2017), partindo de tais definições, propõe o seguinte conceito teórico para a análise sobre o tema:

[Dirigentes públicos são] Ocupantes, por tempo determinado, de cargos de direção de primeiro e segundo níveis hierárquicos de organizações públicas dotadas de autonomia de gestão, nomeados pela autoridade política a partir de processos de escolha orientados à aferição das competências técnicas e gerenciais requeridas para o desempenho da função, podendo ser oriundos ou não das carreiras públicas, e devendo atuar orientados à execução e implementação de políticas públicas, provisão direta de serviços e entrega de valor público à sociedade, prestando contas sobre o alcance dos resultados previamente acordados. (ALESSIO, p. 36, 2017).

Segundo o conceito proposto, dirigentes atuam orientados a resultados e à provisão direta de serviços públicos, entregando valor à sociedade e prestando contas sobre os resultados alcançados. Ocupam posições de direção, reportando direta ou indiretamente ao político eleito e possuem autonomia para gerenciar a organização ou unidade organizacional pela qual respondem. Podem ou não ser oriundos das carreiras públicas. Entre tais aspectos, aquele que buscamos ressaltar está no perfil requerido para esses profissionais: não basta serem dotados de competências técnicas para o desempenho de funções dessa natureza e não basta que sejam servidores de carreira; mais do que isso, é fundamental que sejam dotados de competências de gestão específicas, relacionadas ao espaço de direção ocupado.

O Programa Líderes de Gestão Pública compreende o líder como um profissional dotado de ampla experiência em gestão no setor público ou privado e que deseja liderar uma transformação social, assumindo uma posição da alta liderança de órgãos públicos. Deve ter formação superior completa e atender aos critérios de: sólida trajetória profissional e experiência em cargos de liderança; conhecimentos de gestão pública e/ou do setor em questão (ex. educação, saúde, finanças, etc.); propósito e motivações pessoais alinhados aos da posição que assumirá; e competências relevantes para a posição. No caso específico de Londrina, os candidatos foram avaliados nas competências: resiliência e resultados; tomada de decisão; liderança; capacidade de engajamento e influência; capacidade de comunicação; e estabilidade emocional. 


\subsection{SELEÇÃO E ACOMPANHAMENTO DE LIDERANÇAS}

Os dirigentes públicos atuam em espaços denominados cargos de direção pública. A literatura orientada a esses espaços institucionais de direção tem buscado demonstrar a importância da constituição e consolidação de sistemas de alta direção públicos, compreendidos como um conjunto de regras (legislação) e valores orientados não apenas à seleção, mas a todas as etapas de gestão de um dirigente público, como remuneração, retenção, formação, desenvolvimento, avaliação, mobilidade, desvinculação, entre outros.

A atenção a esse tema coincide com o movimento das reformas gerenciais vivenciadas pelas principais democracias ocidentais, uma vez que o sucesso de tais reformas é condicionado, em forte medida, à existência de profissionais dotados de um conjunto de competências de gestão orientadas ao alcance de resultados e à eficiência (LONGO, 2002). Desse modo, diversos países vêm estruturando e fortalecendo sistemas de alta direção pública, que buscam tratar distintamente o grupo de profissionais ocupantes de posições no alto escalão governamental, diferenciando-os do restante da burocracia pública e estabelecendo regras específicas para sua atuação (KUPERUS; RODE, 2008; OCDE, 2008, 2003).

A atenção a esse tema vem sendo observada tanto nas democracias avançadas quanto em países da América Latina. No entanto, há diferenças importantes entre os dois grupos de países. Enquanto nos primeiros as reformas orientadas ao alto escalão governamental buscam conferir flexibilidades de gestão a uma burocracia historicamente bastante consolidada, mas nem sempre orientada aos resultados que o governo pretende alcançar, na América Latina o desafio é duplo: ao mesmo tempo, esforços são direcionados para a constituição, mas também para a consolidação dessa burocracia pública e para a profissionalização dos espaços específicos de direção. Além disso, no segundo caso, há a tradição histórica da nomeação estritamente discricionária para cargos de direção, prática que vem sendo crescentemente combatida em nome da maior profissionalização e eficiência da atuação governamental (BANCO INTERAMERICANO DE DESENVOLVIMENTO, 2014, 2006; OCDE, 2008, 2003).

Na América Latina, merece destaque o caso do Sistema de Alta Direção Pública (SADP) do Chile, reconhecido internacionalmente pelos avanços alcançados e que, desde sua implantação em 2003, vem desenvolvendo ações permanentes no sentido de aperfeiçoar seus instrumentos de seleção e gestão de dirigentes públicos.

No Chile, mais de $90 \%$ dos cargos de direção são providos a partir de um processo de seleção pública e transparente, que busca “colocar os profissionais certos 
nos lugares certos”. Motivado por uma grave crise política e concebido a partir de um acordo entre governo e oposição, o sistema chileno desenvolve um conjunto de ações orientadas a selecionar, gerenciar e avaliar seus dirigentes, entendidos como um grupo específico e distinto dos demais servidores. Para cada cargo de direção, que pode ser de primeiro ou de segundo nível hierárquico - sendo o primeiro aquele que responde diretamente ao Ministro de Estado -, é realizado um longo e cuidadoso processo de análise das candidaturas pela Direção Nacional do Serviço Civil, órgão central de gestão de pessoas do Governo do Chile, e pelo Conselho de Alta Direção, formado por representantes do Governo e da oposição, escolhidos pelo Presidente e aprovados por dois terços do Congresso. Ao final da seleção, são entregues até quatro nomes para o Presidente e Ministros para a nomeação (ALESSIO, 2013; ALESSIO; PACHECO, 2013; SILVA DURÁN, 2011; LONGO, 2009).

Essa experiência demonstra um exemplo bem-sucedido de uma prática de seleção profissional, na qual são aferidas as competências específicas de gestão dos candidatos, segundo os desafios específicos de cada cargo de direção, mas, ao mesmo tempo, é respeitada a prerrogativa da livre nomeação do Presidente da República. Para o ex-Presidente chileno Sebastián Piñera: “[O SADP] equilibra a seleção por mérito com a governabilidade democrática [...] Ao mesmo tempo, o sistema busca garantir que a administração do Estado responda às diretrizes do governo eleito pela cidadania.” (CHILE, 2003, tradução nossa).

A seleção do Secretário Municipal de Educação de Londrina parte dessa mesma concepção: promover insumos para a decisão política, mas sem combatê-la ou desvalorizá-la. Dessa forma, conta com um processo de seleção de lideranças que busca auxiliar os agentes políticos na escolha dos profissionais mais aptos a ocuparem os cargos de direção das estruturas governamentais, sendo capazes de responder aos desafios do cargo, ao mesmo tempo que orientam sua atuação para a entrega de resultados.

A experiência de Londrina, assim como o Programa Líderes de Gestão Pública são desenvolvidos pelo Vetor Brasil, em parceria com diferentes governos de todo o País. Nesse sentido, em vez de enfatizar todas as dimensões constitutivas de um sistema de alta direção pública governamental, busca induzir e apoiar governos em duas dimensões principais: na etapa de seleção das lideranças públicas, foco e objeto deste artigo, e na etapa de desenvolvimento e acompanhamento dos profissionais selecionados e nomeados. Ambas as dimensões dialogam com a literatura internacional, pois estão ancoradas no princípio de que a atuação do dirigente público deve estar necessa- 
riamente alinhada à definição clara dos resultados a serem entregues e se desenvolver em espaços nos quais sejam exercidas funções específicas de direção.

\subsection{MAPA DE COMPETÊNCIAS}

A seleção, o desenvolvimento e o acompanhamento de lideranças do Programa de Líderes em Gestão Pública e da experiência de Londrina partem de um princípio teórico e metodológico fundamental que guia as ações retratadas pela literatura internacional: compreende a dimensão das competências específicas de gestão como eixo fundamental norteador de todos os processos desenvolvidos, desde o recrutamento e escolha da liderança, até sua desvinculação do cargo (LONGO, 2010, 2002; KUPERUS; RODE, 2008; OCDE, 2008, 2003).

Uma descoberta transcendente será que tais qualidades vão
mais além dos conhecimentos técnicos especializados que se
haviam considerado tradicionalmente como determinantes da
qualificação profissional, para considerar motivos, traços de
carácter, conceitos pessoais, atitudes ou valores, habilidades
e capacidades cognitivas ou de conduta. [...] Isto converte as
competências em um eixo central dos sistemas de gestão de
pessoas, tal como hoje se entende e pratica em um número cres-
cente de empresas e organizações de todo tipo. (LONGO, 2002,
p. 5, tradução nossa).

A importância central dessa dimensão parte da compreensão de que o dirigente público, conforme discutido anteriormente, não se confunde com um profissional essencialmente técnico, nem com uma figura predominantemente política. Ao contrário, constitui um ator distinto no âmbito das estruturas governamentais, que atua movido por um ethos específico, voltado à eficiência e à criação de valor público e que, para tanto, deve possuir um conjunto de competências específicas de direção.

Moore (1995) oferece um modelo analítico que é referência para compreender esse ethos específico de atuação. Segundo esse modelo, os dirigentes devem ser dotados de três competências de gestão e, a partir de tais competências, guiar sua atuação em direção à criação de valor público:

a) gestão estratégica: capacidade de refletir estrategicamente, inovar e reformular para que possa ser criado o máximo valor público; 
b) gestão do entorno político: capacidade de obter legitimidade política de seu entorno político - superiores, outros dirigentes, grupos de interesse, cidadãos, mídia, ou seja, atores internos ou externos à organização -, a fim de conseguir apoio e recursos necessários para que possa desenvolver sua estratégia;

c) gestão operacional: capacidade para conseguir que a organização que dirige, composta pelo conjunto de meios e recursos sob sua autoridade formal, atue com foco nos objetivos e se responsabilize pelos resultados.

Alessio (2017), a partir de Longo (2007) e Pacheco (2011), ilustra, conforme a Figura 1, que o dirigente público pode ter sua atuação marcada por diferentes combinações entre essas três competências, ora desempenhando um papel mais político e menos operacional, ora desempenhando atribuições de direção que requerem um perfil mais voltado à execução de políticas públicas e a assuntos internos da organização. Tais competências, portanto, constituem uma referência para a compreensão do dirigente e para nortear os processos orientados à sua seleção e desenvolvimento, mas devem ser compreendidas como aspectos dinâmicos de sua atuação.

Figura 1 - Um modelo integral de direção pública e suas variações possíveis
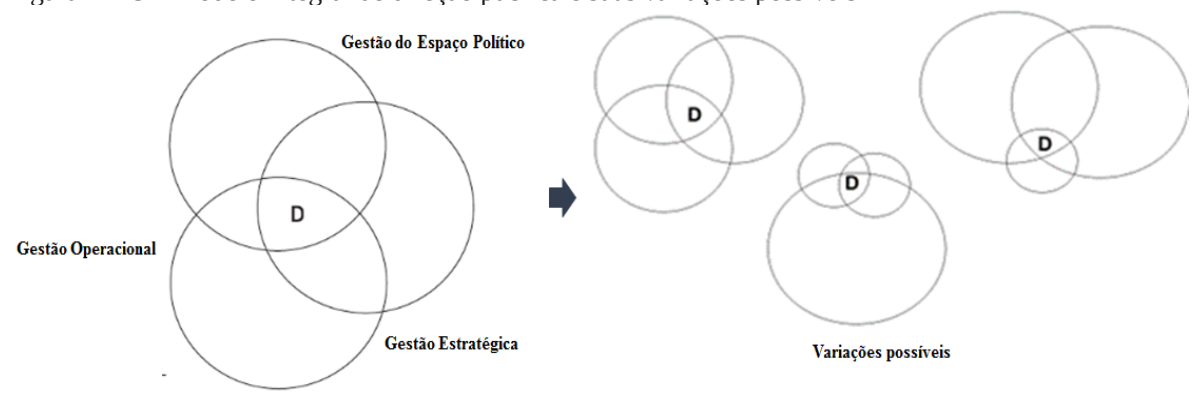

Fonte: Alessio (2017, p. 35).

Com o objetivo de estruturar um processo seletivo que tenha como base evidências e dados mensuráveis, a fim de selecionar os candidatos mais aderentes aos perfis e desafios do setor público, o Vetor Brasil estrutura todos os seus processos de seleção com base na avaliação por competências. Para tal, toma como premissa o conceito de competência como um conjunto de conhecimentos, habilidades e atitudes que justificam o alto desempenho do indivíduo (FLEURY; FLEURY, 2001). 
A seleção dos líderes de gestão pública, incluindo a de profissional para a posição de Secretário Municipal de Educação de Londrina, estrutura-se a partir de um mapa de competências orientado a aferir o perfil mais aderente ao cargo de liderança para o qual se realiza a seleção pública. Tal modelo se baseia na definição de competências centrais, cada uma delas descrita e explicada no Quadro a seguir.

Quadro 1 - Mapa de Competências do Programa Líderes de Gestão Pública

\begin{tabular}{|c|c|c|c|}
\hline Competência & Descrição & Relevância & $\begin{array}{c}\text { Indicadores de } \\
\text { avaliação }\end{array}$ \\
\hline $\begin{array}{l}\text { Resiliência e } \\
\text { Resultados }\end{array}$ & $\begin{array}{l}\text { Capacidade para enfrentar } \\
\text { resistência e contornar adver- } \\
\text { sidades para entregar resulta- } \\
\text { dos. Habilidade para, em caso } \\
\text { de crise, saber como agir e } \\
\text { reverter a situação. } \\
\text { Impulsiona melhorias e os } \\
\text { resultados, mesmo diante de } \\
\text { mudanças e contextos ad- } \\
\text { versos }\end{array}$ & $\begin{array}{l}\text { O Líder provavelmen- } \\
\text { te enfrentará bastante } \\
\text { resistência e terá que } \\
\text { contornar adversi- } \\
\text { dades para entregar } \\
\text { resultados; em caso } \\
\text { de crise, deverá saber } \\
\text { como agir e reverter a } \\
\text { situação }\end{array}$ & $\begin{array}{l}\text { - Como atinge os objeti- } \\
\text { vos, mesmo em situações } \\
\text { adversas, e como propõe } \\
\text { alternativas } \\
\text { - Como ocorre o processo } \\
\text { pessoal de recuperação } \\
\text { após fracasso, tanto em } \\
\text { relação à estabilidade } \\
\text { emocional quanto a resul- } \\
\text { tados atingidos }\end{array}$ \\
\hline Liderança & $\begin{array}{l}\text { Capacidade para inspirar e } \\
\text { gerir a equipe, conquistar a } \\
\text { confiança, motivar e desenvol- } \\
\text { ver o time para atingimento } \\
\text { das metas e objetivos }\end{array}$ & $\begin{array}{l}\text { O Líder precisará ge- } \\
\text { rir um time e rapida- } \\
\text { mente, conquistar sua } \\
\text { confiança, motivando- } \\
\text {-o e desenvolvendo-o } \\
\text { para o atingimento } \\
\text { das metas e objetivos }\end{array}$ & $\begin{array}{l}\text { - Como delega tarefas } \\
\text { - Como compartilha e } \\
\text { acompanha objetivos/ } \\
\text { metas } \\
\text { - Alinhamento de seu } \\
\text { estilo de liderança com a } \\
\text { cultura da organização } \\
\text { - Habilidade para mobili- } \\
\text { zar o time para atingir os } \\
\text { objetivos }\end{array}$ \\
\hline $\begin{array}{l}\text { Tomada de } \\
\text { Decisão }\end{array}$ & $\begin{array}{l}\text { Capacidade para tomar de- } \\
\text { cisões de forma autônoma } \\
\text { e pragmática para assumir } \\
\text { a responsabilidade por suas } \\
\text { ações e calcular os riscos ao } \\
\text { tomar decisões, principalmen- } \\
\text { te controversas }\end{array}$ & $\begin{array}{l}\text { O Líder precisará } \\
\text { tomar decisões de } \\
\text { diferentes magni- } \\
\text { tudes, muitas vezes } \\
\text { com informações } \\
\text { incompletas ou até } \\
\text { conflitantes; precisará } \\
\text { assumir a responsabi- } \\
\text { lidade por suas ações } \\
\text { e calcular o risco ao } \\
\text { tomar decisões con- } \\
\text { troversas }\end{array}$ & $\begin{array}{l}\text { - Qual o processo/ra- } \\
\text { ciocínio para tomada de } \\
\text { decisão } \\
\text { - Envolve a equipe e age } \\
\text { com pragmatismo } \\
\text { - Tomada de decisão de } \\
\text { forma ágil e avaliando } \\
\text { riscos }\end{array}$ \\
\hline $\begin{array}{l}\text { Engaja e } \\
\text { Influencia } \\
\text { Pessoas }\end{array}$ & $\begin{array}{l}\text { Capacidade para engajar, usar } \\
\text { sua influência para conquistar } \\
\text { a confiança da equipe e partes } \\
\text { interessadas envolvidas. Habi- } \\
\text { lidade para resolver conflitos. } \\
\text { Capacidade para influenciar e } \\
\text { criar uma cultura colaborativa } \\
\text { para atingir resultados }\end{array}$ & $\begin{array}{l}\text { O Líder precisará } \\
\text { engajar sua equipe e } \\
\text { partes interessadas } \\
\text { e usar sua influência } \\
\text { para conquistar a } \\
\text { confiança para atingir } \\
\text { resultados e articular } \\
\text { conflitos }\end{array}$ & $\begin{array}{l}\text { - Repertório e experiência } \\
\text { criando senso de time e } \\
\text { estimulando o relaciona- } \\
\text { mento com a equipe } \\
\text { - Capacidade de mobili- } \\
\text { zação, engajamento } \\
\text { - Capacidade de mediar e } \\
\text { solucionar conflitos }\end{array}$ \\
\hline
\end{tabular}




\begin{tabular}{|c|c|c|c|}
\hline Competência & Descrição & Relevância & $\begin{array}{l}\text { Indicadores de } \\
\text { avaliação }\end{array}$ \\
\hline $\begin{array}{l}\text { Capacidade } \\
\text { de Comuni- } \\
\text { cação }\end{array}$ & $\begin{array}{l}\text { Capacidade de se comunicar } \\
\text { de forma direta e efetiva com } \\
\text { diferentes interlocutores }\end{array}$ & $\begin{array}{l}\text { O Líder precisará se } \\
\text { comunicar de maneira } \\
\text { efetiva com interlo-- } \\
\text { cutores distintos e ser } \\
\text { capaz de adaptar sua } \\
\text { comunicação a cada } \\
\text { situação e público }\end{array}$ & $\begin{array}{l}\text { - Adaptabilidade de sua } \\
\text { comunicação } \\
\text { - Clareza de seu raciocí- } \\
\text { nio e construção verbal } \\
\text { - Efetividade de sua } \\
\text { comunicação }\end{array}$ \\
\hline $\begin{array}{l}\text { Estabilidade } \\
\text { Emocional }\end{array}$ & $\begin{array}{l}\text { Capacidade de manter o } \\
\text { equilíbrio mesmo sob grande } \\
\text { pressão }\end{array}$ & $\begin{array}{l}\text { O Líder enfrentará } \\
\text { desafios significati- } \\
\text { vos, sofrerá pressões } \\
\text { de ordem política e } \\
\text { da opinião pública e } \\
\text { possivelmente será } \\
\text { responsável por me- } \\
\text { diar conflitos }\end{array}$ & $\begin{array}{l}\text { - Equilíbrio das emo- } \\
\text { ções ao responder aos } \\
\text { questionamentos e ao ser } \\
\text { confrontado } \\
\text { - Transmite confiança } \\
\text { e equilíbrio na comuni- } \\
\text { cação } \\
\text { - Consegue absorver a } \\
\text { pressão e não contagiar } \\
\text { a equipe }\end{array}$ \\
\hline
\end{tabular}

Fonte: Vetor Brasil (2016).

Como forma de mensurar e identificar as competências ao longo do processo seletivo, foram adotados indicadores de comportamento e uma régua de avaliação. Cada competência utilizada no processo possui indicadores que são utilizados para mensurar o que se deseja avaliar. Esses indicadores são balizados por uma régua que fundamenta a avaliação objetiva de cada candidato.

As competências aqui descritas têm correlação direta com os conhecimentos, as habilidades e as atitudes requeridos de um profissional qualificado para enfrentar os desafios no setor público e para assumir a função em questão. Tais medidas também ajudam a reduzir a influência de componentes de subjetividade durante o processo de seleção, à medida que a avaliação das competências também se baseia na observação do avaliador a respeito do avaliado, tornando o processo mais objetivo, transparente e justo para com todos os candidatos.

Após a realização do mapeamento de competências com os respectivos indicadores e a régua de avaliação, um dos instrumentos escolhidos para medir e avaliar os candidatos é a entrevista por competências. A entrevista por competências é um instrumento de seleção que visa analisar o conteúdo trazido pelo candidato, tendo como base as competências já predefinidas, sendo possível coletar dados e mensurar os indicadores de comportamento que predizem o potencial futuro do candidato de se comportar e performar de acordo com o que é necessário para o cargo em questão. Assim, a partir das respostas dadas pelo candidato e das perguntas realizadas pelo avaliador, o candidato é avaliado com base na régua, que contém quatro níveis de avalia- 
ção, cada qual correspondente a um indicador de comportamento. Por fim, a avaliação final do candidato ocorre a partir de uma análise conjunta de todas as competências em questão, e não apenas na avaliação dos indicadores de forma independente.

Esse modelo é amplamente utilizado em processos de seleção de altos executivos e permite a avaliação objetiva de competências. O modelo adotado também dialoga com as competências propostas por Moore (1995) e busca mensurar e atribuir diferentes pesos para cada uma dessas competências centrais, conforme o cargo de direção/liderança para o qual será realizada a seleção.

Um processo de seleção baseado em competências, com transparência, ética, adequada estruturação das técnicas e instrumentos e uma forte preparação dos profissionais envolvidos pode garantir uma maior probabilidade de sucesso na escolha dos candidatos e, por consequência, o alcance dos resultados de forma harmônica nas equipes. Os processos executados pelo Vetor Brasil destacam-se também pela comunicação constante com todos os candidatos envolvidos e utilização de ferramentas on-line que possibilitam uma avaliação igualitária de todos os candidatos, independentemente de sua localização geográfica, fatores estes que se mostram tendências de seleção em todo o mundo.

\section{METODOLOGIA}

Após o planejamento do processo de seleção, foi iniciada a seleção de candidatos para o cargo de Secretário Municipal de Educação, atividade que incluiu um conjunto de atores, etapas e metodologias que apresentamos nesta seção.

\subsection{ABERTURA E ENCERRAMENTO DAS INSCRIÇÕES}

As inscrições foram abertas em 26 de outubro de 2016, via plataforma on-line (http://www.talentoparaaeducacao.org.br/). No dia 03 de novembro de 2016, uma coletiva de imprensa foi realizada em Londrina para apresentar e divulgar a seleção para o referido cargo. As inscrições para o processo de pré-seleção ficaram abertas até o dia 15 de novembro de 2016.

Sobre essa etapa, cabe ressaltar o sucesso alcançado em um período de tempo considerado muito curto. Após apenas 21 dias dedicados ao recrutamento de candidatos, o encerramento das inscrições resultou num total de 129 inscritos, dos quais 70 residentes em Londrina, todos com currículos profissionais muito qualificados. Entre os inscritos, foram identificados profissionais com vasta experiência no setor 
de educação, incluindo sete ex-secretários municipais dessa área, ligados a diferentes partidos políticos.

\subsection{PRÉ-SELEÇÃO}

A pré-seleção foi constituída por um conjunto de seis subetapas, ilustradas na Figura 2 e apresentadas em detalhes a seguir.

Figura 2 - Etapas do processo de pré-seleção para Secretário Municipal de Educação de Londrina

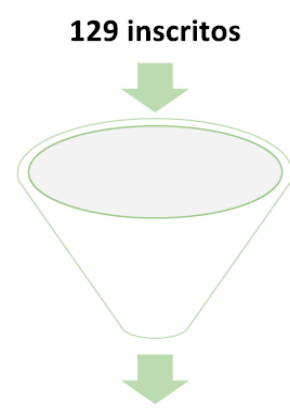

3 finalistas

1 Análise de experiências (CV) e motivações pessoais Avaliação da progressão profissional e das experiências dos candidatos em posições de liderança, além das motivaçöes dos candidatos em participar do processo seletivo

2 Entrevistas por competência + estudo de caso Avaliação das competências apresentadas pelo candidato, de sua capacidade analitica e senso de priorização, por meio de simulação de tomada de decisão, no contexto da gestão da educação

3 Avaliação integrada de competências e perfil Avaliação das preferências comportamentais e das habilidades verbais e numéricas do candidato utilizando a ferramenta Talent $Q$ da Korn Ferry, empresa global de recrutamento de executivos

4 Referências Profissionais Avaliação das experiências profissionais e competências dos candidatos pela ótica de seus gestores diretos em experiências passadas

5 Sabatina com a comunidade educacional de Londrina Avaliação dos candidatos quanto a experiências com educação e gestão, conhecimentos dos desafios da educação em Londrina, bem como de sua capacidade de comunicação

6 Entrevista com Banca Avaliadora Multidisciplinar Avaliação das competências e experiências do candidato por um painel qualificado

Fonte: Vetor Brasil (2017).

\subsection{AVALIAÇÃO INTERNA DOS CANDIDATOS}

Uma renomada empresa global de recrutamento de executivos foi contratada pelo Vetor Brasil para apoiar a avaliação do grande volume inicial de candidatos nas três primeiras subetapas da pré-seleção. Em relação à análise de formação acadêmica, experiências profissionais e motivações, foi verificado se os candidatos inscritos possuíam os requisitos mínimos para sua consideração no processo seletivo, a saber: curso superior completo; ao menos sete anos completos de experiência profissional após a graduação; ao menos três anos completos de experiência em gestão de equipes; e declaração de motivação alinhada aos valores do Vetor Brasil. Dos 129 inscritos, 56 (43\%) apresentaram os requisitos estabelecidos para se qualificarem para a etapa seguinte. 
Na segunda subetapa, foram realizadas entrevistas por competências e estudos de caso com os candidatos aprovados na etapa anterior. Os candidatos realizaram uma entrevista assíncrona (gravada), na qual as perguntas eram disponibilizadas em texto e suas respostas eram gravadas em vídeos de até três minutos e posteriormente avaliadas. As entrevistas consistiram em uma apresentação pessoal, seis perguntas que estimulavam os candidatos a trazerem exemplos de sua vida profissional e pessoal para ilustrar suas competências e experiências, e também contaram com um estudo de caso com a temática de implementação de escolas em tempo integral. As perguntas foram elaboradas com base em quatro das seis competências de avaliação apresentadas anteriormente: resiliência, capacidade de comunicação, engajamento de time e influência e liderança.

A terceira subetapa, a avaliação integrada de competência e perfil, foi realizada por meio de um teste de preferências comportamentais, habilidades numéricas e verbais de propriedade da empresa contratada pelo Vetor Brasil. Os candidatos aprovados na etapa de entrevistas foram encaminhados para a etapa seguinte, que consistia em um teste de preferências comportamentais e habilidades. Esse teste revela a adequação ao cargo de cada candidato, baseado em parâmetros preestabelecidos. Os melhores candidatos apresentaram adequação próxima a 100\% e os de pior desempenho, entre $55 \%$ e $65 \%$.

É importante destacar que nenhum candidato foi aprovado ou eliminado unicamente com base em seu desempenho nesse teste. Tais resultados forneceram subsídios para avaliar os candidatos e levantaram alguns pontos de atenção que puderam ser confirmados nas etapas seguintes da pré-seleção. Os resultados desse teste também deram subsídios para a elaboração dos roteiros das entrevistas a serem realizadas nas demais etapas.

A quarta subetapa foi a análise de referências profissionais. Todos os candidatos aprovados para essa etapa indicaram ao menos uma referência profissional para que o Vetor Brasil contatasse. Os contatos com as referências profissionais foram subsidiados por roteiros estruturados e predefinidos, utilizados com todos os entrevistados. O objetivo dessa etapa foi verificar, a partir de uma fonte distinta, se cada candidato apresentava os pontos de atenção identificados nas etapas anteriores.

Após todas essas etapas, seis candidatos foram convidados às duas últimas subetapas: a sabatina com membros da rede municipal de educação de Londrina e a entrevista com a banca avaliadora.

Cabe destacar que candidatos mais experientes, que possuíssem no mínimo 10 anos de experiência profissional, sendo no mínimo sete anos de trabalho com 
gestão de equipes, tiveram a prerrogativa, estabelecida no chamamento da seleção pública (VETOR BRASIL, 2016), de requisitarem sua participação em um processo seletivo simplificado. Ao todo, nove candidatos tiveram sua requisição atendida e participaram dessa modalidade de processo.

A grande distinção do processo simplificado está na substituição das três primeiras subetapas descritas anteriormente por uma entrevista baseada em competências, realizada por telefone com um entrevistador experiente, parceiro do Vetor Brasil. Os entrevistadores convidados foram o sócio da consultoria estratégica Bain \& Company, Ives Moraes, o Deputado Federal e ex-Secretário de Educação de Goiás, Thiago Peixoto, e o sócio da empresa de busca de executivos Egon Zehnder, André Abram.

\subsection{SABATINA COM MEMBROS DA REDE MUNICIPAL DE EDUCAÇÃO}

A sabatina dos seis candidatos aprovados nas etapas anteriores foi realizada com representantes da comunidade educacional de Londrina, representando cada qual um segmento distinto da rede - diretores de escolas de ensino fundamental, diretores de Centros Municipais de Educação Infantil, professores, supervisores pedagógicos e pais de alunos -, responsáveis por elaborar questionamentos aos candidatos finalistas de acordo com critérios previamente recomendados pelo Vetor Brasil.

Cada candidato foi sabatinado por uma hora, e as sabatinas foram realizadas em dois dias consecutivos, com intervalos entre cada sessão para análise e avaliação de cada candidato. Ao final, o Vetor Brasil compilou os pontos de vista de todos os presentes, o que gerou insumos para os questionamentos na entrevista com a banca.

A sabatina não foi uma etapa eliminatória, mas contribuiu para a observação do candidato sob pressão e respondendo a questionamentos específicos sobre educação e sobre seus planos para Londrina. A experiência desse encontro foi marcante e trouxe a dimensão da relevância que a educação tem para a população da cidade, bem como a atração que exerce entre profissionais do setor de todo o País. Alguns candidatos de outras regiões do Brasil se deslocaram até Londrina, visitaram escolas, conversaram com professores e alunos e estudaram sobre os desafios do setor no Município em antecipação de sua sabatina. 


\subsection{ENTREVISTA COM BANCA COMPOSTA POR ESPECIALISTAS EM EDUCAÇÃO}

A etapa seguinte foi a entrevista dos seis candidatos pré-selecionados por uma banca de notáveis da educação. Essa banca foi formada pelo professor da FGV-Rio e ex-ministro da Educação, Henrique Paim; pelo secretário nacional de Educação Básica do MEC, Rossieli Soares; pela diretora da PUC-PR, campus Londrina, e ex-reitora da Universidade Estadual de Londrina (UEL), Nádina Moreno; pelo vice-presidente do Conselho Estadual de Educação do Paraná, Paulo Schmidt; pela professora e ex-Secretária de Educação de Foz do Iguaçu, Joane Vilela; e pela representante da entidade Todos pela Educação, Priscila Cruz. Essas entrevistas foram realizadas virtualmente, pela internet, com pessoas espalhadas por 10 cidades diferentes. Os membros da banca receberam previamente dossiês de todos os candidatos, com o histórico profissional e os resultados dos testes aplicados nas etapas anteriores, ressaltando pontos fortes e de atenção de cada um.

Com esse documento em mãos, os membros da banca se reuniram previamente e compartilharam impressões e dúvidas que seriam tratadas nas entrevistas com os pré-selecionados. Cada entrevista durou cerca de 20 minutos e, como decorrência do trabalho prévio realizado pelos membros da banca, teve bastante foco e objetividade. Após as entrevistas, os membros da banca se reuniram e definiram, por unanimidade, três candidatos a serem submetidos à avaliação do prefeito eleito. A documentação do processo resultou em um dossiê detalhado sobre os candidatos finalistas. Em 15 de dezembro de 2016, com duração total de 53 dias, foi encerrada a pré-seleção do Secretário Municipal de Educação de Londrina com a apresentação dos três finalistas ao prefeito eleito Marcelo Belinati.

\subsection{ENTREVISTA E RESULTADOS FINAIS}

Por fim, a última etapa do processo, na qual já não houve a participação do Vetor Brasil, consistiu em uma entrevista realizada pelo prefeito Marcelo Belinati e pelo deputado federal Alex Canziani com cada um dos três finalistas. Das entrevistas, resultou a decisão final do prefeito eleito e a posterior nomeação de Maria Tereza Paschoal de Moraes, ex-Secretária de Educação de Ourinhos, SP, como a futura Secretária de Educação de Londrina. 
Maria Tereza é professora e advogada, tendo atuado de 2000 a 2012 em sala de aula. Foi secretária municipal de Educação de Ourinhos (SP) de 2013 até março de 2016. É pós-graduada em Liderança e Gestão Pública pelo CLP/Harvard e é líder RAPS (Rede de Ação Política pela Sustentabilidade). Também possui formação como intérprete de Libras (Língua Brasileira dos Sinais). Maria Tereza aceitou o convite tão logo foi informada sobre a decisão do prefeito e tomou posse como Secretária de Educação do Município de Londrina em $1^{\circ}$ de janeiro de 2017.

Os demais candidatos finalistas tiveram a oportunidade de serem considerados para outras posições dentro da gestão municipal. Um caso notável foi o da Coordenadora Pedagógica Rosana Daliner Acosta Marchese, servidora de carreira da Secretaria de Educação de Londrina havia mais de 14 anos, que obteve excelente desempenho no processo de pré-seleção, mas que não foi selecionada pela Banca Avaliadora para compor a lista de nomes enviada ao prefeito. Por seu excelente desempenho ao longo do processo de pré-seleção, Rosana foi escolhida pela nova Secretária, Maria Tereza, para assumir uma posição de destaque dentro da Secretaria, passando a liderar uma das três grandes áreas da organização, a Assessoria Administrativa, e também foi convidada a integrar o Programa Líderes de Gestão Pública. Esse fato demonstrou que o processo realizado foi capaz não apenas de atrair excelentes profissionais de outras regiões do Brasil, mas também de identificar talentos dentro da própria estrutura da educação pública de Londrina.

\section{APRESENTAÇÃO E DISCUSSÃO DOS RESULTADOS}

A experiência de Londrina enfrentou alguns desafios, traduzidos em aprendizados relevantes para subsidiar ações futuras orientadas a esse tema. O primeiro e mais importante desafio está relacionado à mudança de paradigma sobre o modelo de escolha adotado para o provimento de um cargo de Secretário Municipal de Educação. Essa mudança de paradigma vai de encontro a dois problemas: o primeiro deles, a visão de que toda nomeação política é discricionária e orientada a fins político-partidários; a segunda, a ideia de que a solução para combater tais nomeações está na escolha de dirigentes pertencentes às carreiras públicas. A experiência de Londrina mostra que nem a discricionariedade política e nem a reserva de cargos para servidores são capazes de explicar os desafios em curso; demonstra, ao contrário, a necessidade e a relevância da adoção de processos transparentes, públicos de escolha de profissionais e dotados de instrumentos capazes de aferir as competências específicas de gestão dos futuros dirigentes. 
Em vez da adoção de uma escolha discricionária e sujeita a pressões de interesses políticos, ou, alternativamente, da escolha restrita a servidores públicos da rede municipal de educação, o modelo de seleção de Londrina, concebido e apoiado pelo prefeito Marcelo Belinati e pelo deputado federal Alex Canziani, inovou ao conferir grande racionalidade ao processo de escolha, orientado não apenas às competências técnicas e à experiência profissional dos candidatos - especialmente no tema da educação -, mas, e principalmente, à aferição de suas competências gerenciais. Cabe destaque à sabatina realizada por representantes da rede municipal de educação, adotada como uma das etapas do processo, que resultou em um melhor entendimento da rede em relação à proposta do prefeito. Essa etapa ajudou na mitigação de um dos riscos identificados desde o início dos trabalhos: a resistência natural da rede municipal de educação de Londrina, setor organizado e bem estruturado, que poderia ser refratária à inovação proposta. Esse caso mostrou que paradigmas enraizados na cultura política brasileira podem ser questionados, e novas propostas orientadas a melhores estratégias de escolha de dirigentes públicos podem ser compartilhadas e apoiadas por todos aqueles que desejam contribuir para a melhoria dos serviços prestados aos cidadãos.

Um segundo desafio importante diz respeito à estrutura de remuneração de cargos de direção no setor público, especialmente quando comparada às responsabilidades assumidas pelos dirigentes públicos ordenadores de despesa, sejam elas de ordem administrativa, gerencial ou legal, o que pode levar à dificuldade de atração de maior número de candidatos interessados em assumir os desafios de um cargo como o de Secretário de Educação. No caso de Londrina, a remuneração bruta mensal dos Secretários Municipais é de R\$ 9.800,00 enquanto o orçamento da Secretaria de Educação gira em torno de R\$ 400 milhões. Empresas privadas nacionais com faturamento similar pagam a seus dirigentes um salário médio de $\mathrm{R} \$$ 52.000,00, segundo pesquisa realizada pela consultoria Michael Page em 2015 (MICHAEL PAGE, 2017).

Esse não é um desafio simples de ser superado, mas inovações podem ser propostas como forma de tornar atrativa a atuação de profissionais excepcionais em espaços de direção no setor público. No caso de Londrina, o Programa Líderes de Gestão Pública ofereceu à Secretária Maria Tereza a oportunidade de participar de programas de mentoria e de coaching, direcionados a dar suporte a seu desenvolvimento profissional e orientação de carreira. Maria Tereza hoje tem como mentora a vice-governadora do Ceará e ex-Secretária de Educação do estado, Izolda Cela, uma profissional que é referência em educação básica. Também cabe destacar que o prefeito eleito deu abertura para que o futuro secretário tivesse a oportunidade de criar um grande case de sucesso para sua carreira profissional. 
Outro aspecto a ser destacado trata da relação entre o prefeito eleito de Londrina, que concebeu a proposta de seleção, e o Vetor Brasil, responsável pela condução do recrutamento e pré-seleção de candidatos. Um aspecto central para o sucesso dessa parceria esteve na delimitação clara de responsabilidades entre os envolvidos, formalizada por meio de um memorando de entendimentos assinado antes do início do processo e disponibilizado ao público (VETOR BRASIL, 2016), como é de praxe em todas os projetos e iniciativas realizadas pelo Vetor Brasil. Para o sucesso desse trabalho, foi fundamental a autonomia e independência concedida ao Vetor Brasil para a execução das etapas da pré-seleção, bem como o apoio permanente dos apoiadores do projeto contra interferências políticas indevidas ao longo do processo de seleção, no sentido de garantir sua conclusão, efetivada com a nomeação da Secretária Municipal de Educação. Para garantir esse respeito à sua autonomia, o Vetor Brasil disponibilizou relatórios do andamento das atividades ao prefeito eleito e sua equipe ao longo de todo o processo, dando a necessária transparência às ações desenvolvidas. Da mesma forma, o prefeito Marcelo Belinati e o deputado Alex Canziani apoiaram o projeto, buscando combater críticas contrárias, bem como ressaltar os objetivos pretendidos a partir da realização de uma iniciativa pioneira como esta.

Alguns aprendizados e recomendações para reflexões sobre a implantação de experiências similares pelo Brasil afora dizem respeito: em primeiro lugar, ao Programa Líderes de Gestão Pública, que assim como a seleção realizada em Londrina, direciona seus esforços para o recrutamento e seleção de candidatos, mas também para seu acompanhamento e desenvolvimento. Demonstrou-se que as experiências internacionais extrapolam essas dimensões e buscam estruturar sistemas robustos de alta direção pública orientados a outras ações complementares, voltadas à atuação dos dirigentes públicos: remuneração, avaliação, desvinculação, entre outros. Assim, defende-se que tais aspectos sempre permaneçam sob o olhar dos interessados no tema.

Em segundo lugar, ressalta-se a importância da definição clara sobre quais espaços constituem posições de direção no setor público. Tal definição parte das referências teóricas existentes, mas, ao mesmo tempo, deve atentar para as especificidades de cada organização pública. Autonomia orçamentária, liderança de equipes, definição e compromisso claro com resultados e metas são alguns dos aspectos a serem observados, entre as demais dimensões presentes em um modelo de direção pública.

Por fim, há a necessidade de serem construídas estratégias orientadas a conferir maior atratividade à ocupação dos espaços de direção no setor público, de modo a superar as visões de que tais espaços são necessariamente usados para fins político-partidários, de que envolvem riscos ao dirigente nomeado ou de que constituam 
espaços muito burocráticos e dotados de pouca autonomia de gestão. Ao contrário, espaços de direção no setor público oferecem um potencial extremamente importante para o desenvolvimento de ações com alto impacto de transformação social.

\section{CONCLUSÃO}

Partindo da premissa de que a qualificação da gestão pública e a qualidade dos serviços oferecidos aos cidadãos são determinados pela capacidade de seus líderes, o então prefeito eleito de Londrina, Marcelo Belinati, em parceria com o deputado federal Alex Canziani, que preside a Frente Parlamentar Mista da Educação, idealizou o que veio a ser o primeiro processo seletivo profissional para preenchimento de um cargo de primeiro escalão na gestão pública municipal brasileira, contrariando as corriqueiras trocas de favores e o patrimonialismo que marcam a designação de nomes para esse tipo de investidura. A nova Secretária Municipal de Educação do Município foi escolhida por meio de um processo de avaliação que contou com inscrições abertas ao público, critérios técnicos e objetivos nas diversas etapas de avaliação, foco nas competências gerenciais e absoluta transparência.

Neste texto, buscou-se demonstrar que experiências dessa natureza dialogam diretamente com a literatura internacional sobre o tema. Partem do mesmo pressuposto segundo o qual vem se tornando cada vez mais relevante a adoção de procedimentos e critérios racionais capazes de subsidiar melhores escolhas para ocupantes de cargos de direção no setor público. O eixo central de ações pautadas por essa orientação está na adoção de modelos baseados em competências de gestão, entendidos como aspecto fundamental que orienta tanto a seleção dos candidatos quanto todo o processo de gestão e desenvolvimento que ele vivenciará dentro da estrutura do governo.

O caso de Londrina, nascido com o Programa Líderes de Gestão Pública do Vetor Brasil, orienta sua atuação para duas das principais dimensões de sistemas orientados à alta direção pública: a seleção de candidatos, foco deste trabalho, e as ações voltadas ao seu acompanhamento e desenvolvimento. Sobre a seleção, buscou-se descrever as etapas realizadas, ressaltando o caráter pioneiro da experiência, o papel das lideranças políticas em conceber esse modelo, voltado à profissionalização da educação municipal de Londrina, e o apoio do Vetor Brasil como executor das etapas de avaliação de perfil dos candidatos.

Destaca-se como principal aspecto positivo da experiência o seu pioneirismo, já mencionado. Também se reforça o caráter profissional da escolha, que combina um processo de seleção criterioso, baseado em requisitos técnicos e competências geren- 
ciais, com a decisão e responsabilidade final assumida pelo político eleito. Tal processo de seleção, público e aberto a quaisquer candidatos interessados, traz uma dinâmica de competição saudável para o processo e estimula diversos interessados em atuar à frente de uma organização pública a participarem do certame. O caso de Londrina foi recebido com grande entusiasmo pela mídia e pela opinião pública, de forma geral, e foi bem-sucedido não apenas por atrair grande número de candidatos, mas por concluir a pré-seleção com três nomes potenciais para o exercício da função de direção.

O resultado obtido por Londrina demonstrou que a estruturação e execução assertiva do processo de seleção pode propiciar a escolha de um candidato com distinta qualificação e perfil bem próximo ao concebido pelo chefe do executivo municipal, além de permitir um saudável intercâmbio dentro da gestão pública. Iniciativas como esta podem ser observadas e implementadas por outros governos municipais e estaduais, cabendo a cada administração considerar suas especificidades e necessidades ao lançar mão de iniciativa de tal teor.

O fato de o Secretário Municipal de Educação constituir parte da equipe direta do prefeito de Londrina o diferencia de outros dirigentes mais voltados à implementação de políticas públicas previamente contratualizadas. Nesse caso, o dirigente tem um papel muito mais próximo do nível político e da esfera de formulação das políticas públicas, podendo, para alguns autores, distanciar-se do conceito de dirigente público, ainda que atue também voltado à implantação e execução de ações que geram resultados concretos à população.

Justamente por essa proximidade em relação à principal figura política do município, o cargo de Secretário Municipal de Educação é, historicamente, escolhido por livre discricionariedade do prefeito, o que implica, em muitos casos, que tal escolha seja motivada por acordos político-partidários.

Futuras experiências também devem considerar estratégias alternativas para a promoção de reformas como esta. Londrina é um case de sucesso para a escolha de um cargo de direção, mas alcança uma única posição em todo o governo; mostramos, por outro lado, que o caso do Chile alcança 90\% de todos os cargos de direção do país. Assim, futuras iniciativas podem direcionar seus esforços rumo a reformas mais integrais, ainda que estas sejam implantadas de modo gradual. Além disso, o espaço de direção traz aos reformadores um conjunto amplo de desafios, para além da dimensão da seleção, como a adoção de contratos de resultados que estabelecem claramente os objetivos a serem alcançados durante determinado período de tempo, e que são atrelados a políticas de remuneração variável baseada no desempenho, para citar os mais relevantes. 
São muitos os riscos que envolvem esse trabalho tão complexo como importante. Talvez os dois principais desafios a serem enfrentados sejam a resistência de diversos segmentos e atores em relação às mudanças de paradigma necessárias à superação da visão de que escolhas políticas são necessariamente discricionárias e orientadas por fins político-partidários e a falta de atores que oferecem um serviço de qualidade para os governos que querem utilizar processos profissionais de busca e avaliação de profissionais.

Buscou-se demonstrar, a partir da literatura nacional e internacional, mas principalmente por meio de uma experiência concreta, que a mudança é desejável e possível, e que estratégias específicas podem e devem ser propostas no âmbito dos cargos de direção no setor público. Tais estratégias não combatem a decisão política, desejável em um contexto democrático, nem se opõem ao fortalecimento das burocracias públicas, mas buscam apontar os desafios específicos associados aos espaços de direção no setor público e desenhar estratégias de seleção e gestão de dirigentes coerentes com os resultados que se deseja alcançar.

\section{REFERÊNCIAS}

ALESSIO, M. F. Dirigentes públicos, política e gestão: o Sistema de Alta Direção Pública chileno. 2013. Dissertação (Mestrado em Administração Pública e Governo)-Fundação Getulio Vargas, Rio de Janeiro, 2013.

ALESSIO, M. F. Estratégias de escolha de dirigentes públicos no Brasil: alcances e limitações das experiências recentes à luz do debate internacional. 2017. Tese (Doutorado em Administração Pública e Governo)-Fundação Getulio Vargas, Rio de Janeiro, 2017.

ALESSIO, M. F.; PACHECO, R. O sistema de Alta Dirección Pública do Chile: política e gestão. In: CONGRESO INTERNACIONAL DEL CLAD, 18., 2013, Montevidéu. Anais... Montevidéu, 2013.

BANCO INTERAMERICANO DE DESENVOLVIMENTO. Informe sobre la situación del servicio civil en América Latina. Banco Interamericano de Desarrollo. Diálogo Regional de Políticas. Washington, DC, 2006.

BANCO INTERAMERICANO DE DESENVOLVIMENTO. In: VELARDE, C. C.; LAFUENTE, M.; SANGINÉS, M. (Ed.). Al servicio del ciudadano: una década de reformas del servicio civil en América Latina (2004-2013). Washington, DC, 2014. 
CHILE. Ley n. 19.882, de 23 junio de 2003. Regula nueva política de personal a los funcionarios públicos que indica. Biblioteca del Congreso Nacional, 2003.

FLEURY, M. T. L.; FLEURY, A. Construindo o conceito de competência. Revista de Administração Contemporânea, Curitiba, v. 5, 2001. Disponível em: <http://www.scielo.br/scielo.php?script=sci_arttext\&pid=S1415-65552001000500010\&lng=en\&nrm=iso>. Acesso em: 20 nov. 2017.

KUPERUS, H.; RODE, A. Top public managers in Europe: Management and working conditions of the senior civil servants in the European Union member states. Study commissioned by the French EU presidency. Maastricht, 2008.

LONGO, F. Ejes vertebradores de la gobernanza en los sistemas públicos. Un marco de análisis en clave latinoamericana. Revista del CLAD Reforma y Democracia, n. 46, 2010. 45-56.

LONGO, F. El desarrollo de competencias directivas en los sistemas públicos: una prioridad del fortalecimiento institucional. In: CONGRESO INTERNACIONAL DEL CLAD, 7., 2002, Lisboa. Anais... Lisboa, 2002.

LONGO, F. Mérito e flexibilidade. A gestão das pessoas no setor público. São Paulo: Edições Fundap, 2007.

LONGO, F. Mérito e flexibilidade revisitados. In: MEDEIROS, P. C.; LEVY, E. (Org.). Novos caminhos da gestão pública: olhares e dilemas. Rio de Janeiro: Qualitymark, 2009.

MICHAEL PAGE. Pesquisa Salarial - Presidentes e Diretores Executivos - Brasil 2015. Disponível em: <http://www.michaelpage.com.br/sites/michaelpage.com. br/files/150429\%20-\%20pesquisa_exec_port.pdf>. Acesso em: 20 nov. 2017.

MOORE, M. H. Creating public value: Strategic management in government. Cambridge, Mass: Harvard University Press, 1995.

OCDE. Managing senior management: senior civil service reform in OECD member countries. Paris: Background Note, 2003.

OCDE. The senior civil service in national governments of OECD countries. Paris, 2008. 
PACHECO, R. Dirigentes públicos, DAS e cargos em comissão. Material da Disciplina Gestão Pública no Brasil: Políticas e Desafios Contemporâneos, ministrada no primeiro semestre de 2011 no Curso de Mestrado em Administração Pública e Governo. Fundação Getúlio Vargas, São Paulo, 2011.

PACHECO, R. Organizando o debate: dirigentes públicos no Brasil. In: CONGRESSO CONSAD DE GESTÃO PÚBLICA, 1., 2008, Brasília, DF. Anais... Brasília, DF: 2008. p. 1-16.

SILVA DURÁN, F. Profesionalización de la función pública: la experiencia chilena (Reforma 2003-2011). Desigualdade \& Diversidade, Rio de Janeiro, n. 9, p. 23-33, 2011.

VELARDE, J. C. C.; LAFUENTE, M.; SANGINÉS, M. (Ed.). Al servicio del ciudadano. Una década de reformas del servicio civil en América Latina (2004-13). Banco Interamericano de Desarrollo. Washington, DC: 2014.

VETOR BRASIL. Case de Londrina. Materiais sobre o projeto. 2017. Disponível em: <http://www.vetorbrasil.com/?page_id=981>. Acesso em: 20 nov. 2017.

VETOR BRASIL. Documento interno. Mapa de Competências do Programa Líderes de Gestão Pública. 2016. Disponível em: <http://www.vetorbrasil.com>. Acesso em: 20 nov. 2017.

\section{Como citar este artigo:}

\section{ABNT}

LAMELO, Thiago Miquel et al. Processo seletivo público para escolha de secretário municipal: análise da experiência da Cidade de Londrina, PR. RACE, Revista de Administração, Contabilidade e Economia, Joaçaba: Ed. Unoesc, v. 16, n. 3, p. 235-258, 2017. Edição Especial. Disponível em: <http://editora.unoesc.edu.br/index.php/race>. Acesso em: dia/mês/ano.

\section{APA}

Lamelo, T. M., Mendes, J. T., Alessio, M. F., \& Andrade, T. K. B. (2017). Processo seletivo público para escolha de secretário municipal: análise da experiência da Cidade de Londrina, PR [E. especial]. RACE, Revista de Administração, Contabilidade e Economia, 16(3), 235-258. Recuperado em dia/mês/ano, de http://editora.unoesc.edu. br/index.php/race 